\title{
Discontinuation and reinitiation patterns of osteoporosis treatment among commercially insured postmenopausal women
}

This article was published in the following Dove Press journal:

International Journal of General Medicine

5 November 2013

Number of times this article has been viewed

\section{Akhila Balasubramanian' \\ MAlan Brookhart ${ }^{2}$ \\ Vamshidar Goli' \\ Cathy W Critchlow'}

'Amgen Inc, Thousand Oaks, CA, USA; ${ }^{2}$ University of North Carolina at Chapel Hill, Chapel Hill, NC, USA
Correspondence: Cathy Critchlow Amgen Inc, One Amgen Center Drive, MS 24-2-A, Thousand Oaks,

CA 91320 , USA

Tel +l 8054478525

Fax + I 805447 I984

Email ccritchl@amgen.com
Objective: Poor adherence to chronic medications is common and compromises medication effectiveness. We sought to describe longitudinal patterns of osteoporosis medication use.

Study design: This was a retrospective observational cohort study using 2005-2009 data from a large, commercially insured population.

Methods: Patients were women aged $\geq 55$ years initiating osteoporosis therapy who had a $\geq 12$-month (baseline) period with no osteoporosis therapy claims preceding initiation, and $\geq 24$ months follow-up after therapy initiation. Discontinuation was defined as a gap $>60$ days (varied in sensitivity analyses) in prescription claims. Reinitiation was defined as a prescription claim for the same or different osteoporosis therapy following the therapy gap. Discontinuation and reinitiation patterns were described using Kaplan-Meier analysis. Multivariable Cox regression assessed the impact of baseline factors on reinitiation.

Results: Of the 92,839 patients, $45 \%, 58 \%$, and $70 \%$ discontinued therapy at 6,12 , and 24 months, respectively, following initiation. Of the discontinuers, $46 \%$ reinitiated therapy, with the majority doing so within 6 months of discontinuation. Women were less likely to reinitiate therapy if they were older $(P<0.0001)$ or were hospitalized during baseline $(P=0.0007)$. Women who discontinued treatment early ( $<6$ months) following initiation were less likely to reinitiate $(P<0.0001)$ and remained on therapy for shorter periods following reinitiation. Depending on the available observation time, the median time on therapy following reinitiation was 58-193 days. Study findings did not change appreciably in sensitivity analyses.

Conclusion: Many patients stop and restart treatment for osteoporosis. A better understanding of determinants of treatment stopping and restarting could inform adherence improvement efforts.

Keywords: bisphosphonates, persistence, adherence, osteoporosis, therapy utilization

\section{Introduction}

Osteoporotic fractures, particularly those at the hip, are debilitating and are associated with prolonged disability and increased mortality. ${ }^{1,2}$ For postmenopausal women $\geq 50$ years of age, it is estimated that one in every two women will develop an osteoporotic fracture in her lifetime and $20 \%$ of those with a hip fracture will die within a year of the fracture. ${ }^{3}$ Several medications are available for preventing and treating osteoporosis, bisphosphonates (BPs) being the most common. However, patient adherence to these medications is generally poor. Poor adherence with therapy is associated with decreased effectiveness and increased fracture risk. ${ }^{4}$

The term "adherence" is used to reflect both persistence (the duration of time from therapy initiation to discontinuation) and compliance (the extent to which a patient 
acts in accordance with the prescribed interval and dose of a treatment regimen). ${ }^{4}$ As osteoporosis is a chronic disease that worsens with age, most osteoporosis therapies, with the exception of the anabolic agent teriparatide, are intended for long-term use with decisions regarding treatment duration based on the clinician's judgment of the patient's fracture risk. ${ }^{5-7}$ Safety concerns over long-term exposure to BPs have recently prompted the suggestion of drug holidays following 3-5 years of BP exposure among patients at lower fracture risk. ${ }^{5,6}$ Recent investigations of BPs suggest that high compliance with at least 2 years of treatment is required for fracture protection to remain following therapy discontinuation, ${ }^{8}$ and several previous studies have emphasized the importance of good adherence for effective fracture protection. ${ }^{4}$ Yet, over the last decade, studies have consistently reported that patient adherence to osteoporosis medication is generally poor, with persistence of only about 6-9 months and average compliance of approximately $60 \%{ }^{4,9,10}$

While many studies have investigated persistence and adherence rates for osteoporosis therapies, most studies have used relatively short follow-up intervals (typically 12 months), and have not typically reported on utilization patterns following the first interruption in therapy. ${ }^{11-20}$ Predictors of different therapy utilization behaviors are also not well understood. Given the recent guideline updates on duration of osteoporosis therapy, ${ }^{5}$ as well as the relatively larger variety of therapeutic agents that have become available over the last decade, understanding longer-term utilization is increasingly important. A few studies have reported rates of reinitiation following an initial interruption in therapy, ${ }^{17,18,21,22}$ and Brookhart et al assessed factors associated with reinitiating therapy following a treatment gap, with the intention of better understanding the cycling pattern of therapy use. ${ }^{21}$ There is a need to build on these initial findings using more current data and longer follow-up periods. In the present study, we use recent data from a commercially insured population of relatively young postmenopausal women in the United States to describe longer-term utilization patterns of osteoporosis therapy, including persistence, discontinuation or interruption of therapy, reinitiation, and factors associated with reinitiating therapy.

\section{Methods}

This study was conducted in a population of commercially insured women using the MarketScan ${ }^{\circledR}$ administrative claims database (Truven Health Analytics, Ann Arbor, MI, USA). MarketScan ${ }^{\circledR}$ represents individuals across the US receiving health insurance coverage from large employers. Data from commercial health plans as well as Medicare Supplement coverage for the period January 2005 through December 2009 were included in this analysis.

Women aged $\geq 55$ years with at least one prescription claim for any of the following osteoporosis medications were eligible for the study: oral BPs (risedronate, alendronate, and ibandronate), raloxifene, teriparatide, and calcitonin. The first filled prescription claim for any of these qualifying osteoporosis therapies marked the "index date." Patients were required to have data available during a pre-index baseline period of 12 months with no filled prescription claims for any osteoporosis therapy, and a post-index follow-up period of $\geq 24$ months. Patients were excluded if they had medical claims or evidence of BP use for Paget's disease at any point in the study period.

Therapy discontinuation was defined as a gap in osteoporosis medication claims exceeding a prespecified allowable refill gap period. The refill gap period was defined as the maximum length of time permissible between the depletion date of the supply of an osteoporosis prescription claim and the fill date for the next osteoporosis prescription claim. If a prescription claim was filled before the previous claim's supply was depleted, the clock was reset to the last date marked by supply rather than the premature fill date of the next prescription claim. The allowable refill gap was 60 days in the primary analysis.

Patients who had no refill gaps exceeding the allowable refill gap period were classified as "continuous users." Patients who had refill gaps exceeding the allowable refill gap period were classified as "discontinuers," "early discontinuers" were patients who had been on therapy for $<6$ months prior to discontinuation, while "late discontinuers" had been on therapy for $\geq 6$ months prior to discontinuation. Discontinuers were further distinguished as those who did versus did not reinitiate therapy. Reinitiation was defined by the presence of a prescription claim for any osteoporosis medication following a period of discontinuation (any prescription therapy indicated for treating postmenopausal osteoporosis with the exceptions of hormone replacement therapy, vitamin D, and calcium, qualified for reinitiation). Time spent on and off therapy was described by calculating the following: (1) persistence, or time on therapy prior to the first discontinuation event; (2) time between discontinuation and reinitiation; and (3) time on therapy following reinitiation. In these calculations, the allowable refill gap period immediately preceding a discontinuation event was included in the time off therapy.

\section{Statistical methods}

Demographic, behavioral, and clinical characteristics were described separately for continuous users, discontinuers 
who remained off therapy, and discontinuers who reinitiated therapy. Mean, standard deviation, median, and range were reported for continuous variables, and frequency distributions were reported for categorical variables.

The Kaplan-Meier method ${ }^{23}$ was used to estimate the survival distribution of (1) time until discontinuation, (2) time to reinitiation among discontinuers, and (3) time on therapy following reinitiation. Among discontinuers, a multivariable Cox regression model was used to assess factors associated with reinitiating therapy. ${ }^{24}$ Time to therapy reinitiation served as the outcome, and clinical and behavioral characteristics, measured during the 12-month baseline period preceding therapy initiation, were assessed as potential predictors.

\section{Sensitivity analyses}

Two sensitivity analyses were conducted. In one, the allowable refill gap period was varied between 30 and 90 days. In the other, analyses were repeated in a study cohort that required $\geq 12$ months rather than $\geq 24$ months of postindex follow-up. The main study population, which had $\geq 24$ months of continuous enrollment in the database, could potentially reflect a healthier and more stable population than the larger population of osteoporosis therapy users in this claims database. Thus, this sensitivity analysis addressed the potential selection bias that may have arisen from requiring 24 months of follow-up.

All analyses were performed using SAS 9.2 software (SAS Institute Inc, Cary, NC, USA). The data contained in the MarketScan ${ }^{\circledR}$ database were de-identified and fully compliant with the Health Insurance Portability and Accountability Act (HIPAA) privacy regulations.

\section{Results}

A total of 92,839 women met all the selection criteria and had complete and evaluable data (Figure 1). The mean age of patients was 67.7 years, with almost half being younger than 65 years (Table 1). During the 12-month baseline period, $30.4 \%$ of the women had a diagnosis of osteoporosis, $3.8 \%$ had a diagnosis of osteoporotic fracture, and $62.1 \%$ underwent bone mineral density (BMD) testing. Fourteen percent of the women were hospitalized at least once during baseline. Oral BPs were the most common osteoporosis therapy prescribed at index $(n=79,713$, or $86 \%)$. Among these women, the weekly dosing regimen was the most common (74\%), followed by the monthly dose $(25 \%)$.

Of the 92,839 patients, 64,593 discontinued therapy. Compared to continuous users, discontinuers (both those who remained off therapy and those who reinitiated) were more likely to have had a greater number of comorbidities and concomitant medications and to have been hospitalized, and less likely to have undergone BMD testing during the baseline period (Table 1).

At $6,12,18$, and 24 months following therapy initiation, $45 \%, 58 \%, 66 \%$, and $70 \%$ of patients had discontinued therapy, respectively (Figure 2A). Among discontinuers, the median time between therapy initiation and discontinuation was 94 days. Of the 64,593 patients who discontinued therapy, 29,720 (46.0\%) returned to therapy during the study period. Late discontinuers were more likely to return to therapy and did so sooner than early discontinuers $(P<0.0001)$ (Figure 2B). Discontinuers who reinitiated therapy did so fairly quickly following discontinuation. Among patients who had at least 12 months of observation time remaining following discontinuation, $38.3 \%$ and $5.2 \%$ returned to therapy within 6 months and from 6-12 months, respectively; $56.4 \%$ remained off therapy throughout the observation period following discontinuation.

Following therapy reinitiation, patients remained on therapy for approximately 2-6 months before a second discontinuation event (ie, another interruption in therapy of $\geq 60$ days). Late discontinuers were more likely than early discontinuers to remain on therapy for longer periods following reinitiation. Among patients who had $\geq 6$ months of observation time following reinitiation, late discontinuers remained on therapy for a median of 180-193 days following reinitiation, compared with 90-114 days for early discontinuers (Table 2).

The multivariable Cox proportional hazards analysis indicated that older women were less likely to reinitiate therapy following discontinuation compared to younger women, even after adjusting for other clinical and behavioral factors. Compared to women aged 55-59 years, those aged $\geq 70$ years were $12 \%-24 \%$ less likely to reinitiate therapy (Table 3 ). Women who had, compared to those who had not, been hospitalized during the baseline period were also less likely to reinitiate therapy (hazard ratio $[\mathrm{HR}]=0.94,95 \%$ confidence interval [CI]: 0.90-0.97). Women with versus without a diagnosis of osteoporosis and those who did versus did not undergo BMD screening by dual-energy X-ray absorptiometry (DXA) test during the baseline period were marginally more likely to reinitiate therapy $(\mathrm{HR}=1.07,95 \% \mathrm{CI}: 1.04-1.10$ for osteoporosis diagnosis; $\mathrm{HR}=1.03,95 \% \mathrm{CI}: 1.00-1.06$ for BMD screening).

Sensitivity analyses yielded findings that were qualitatively similar to those in the main analysis. As would be expected, the rates of discontinuation decreased with longer 


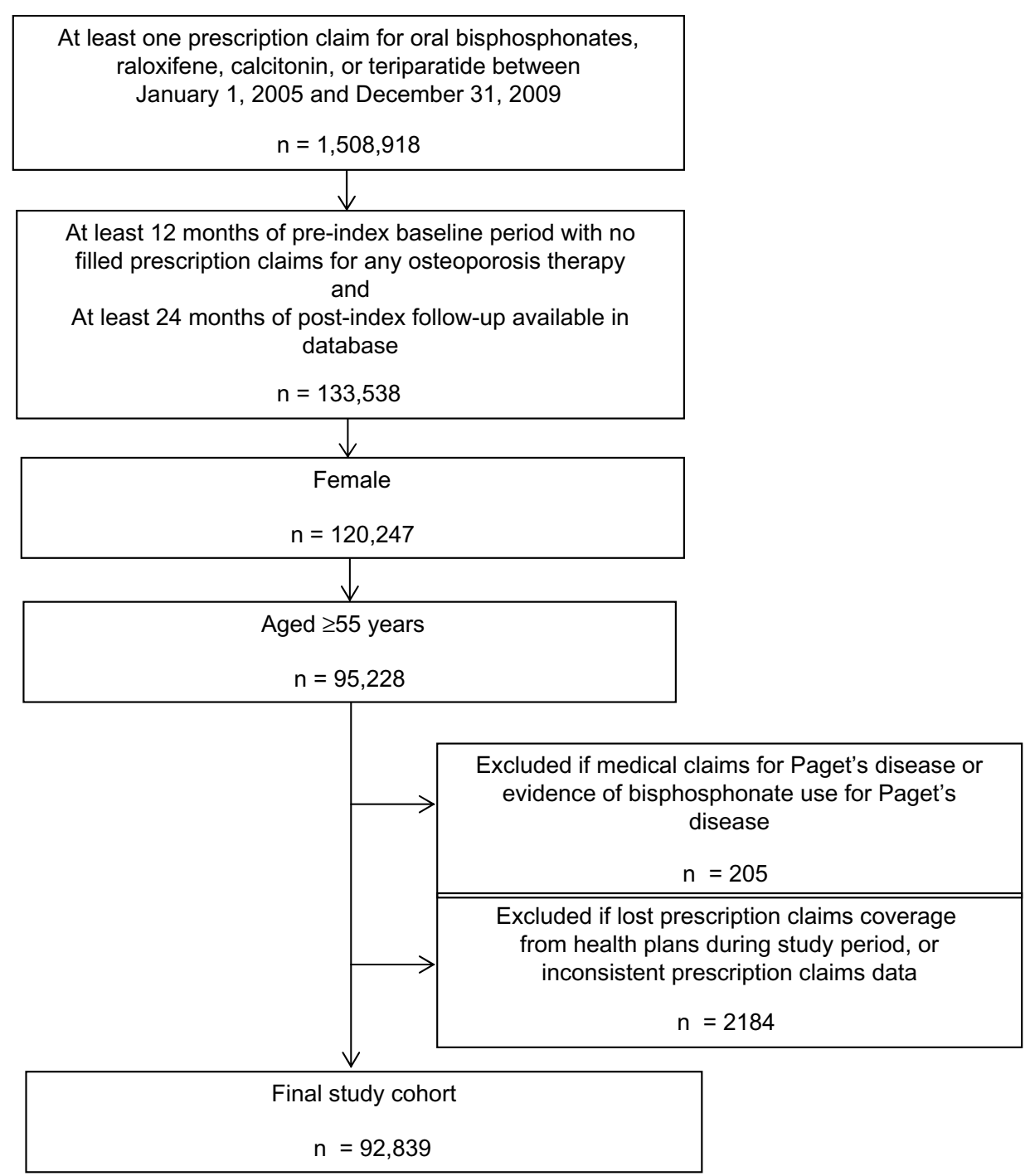

Figure I Patient selection flowchart.

allowable gap periods. When the allowable gap period was varied from 30 to 60 to 90 days, the rates of discontinuation at 12 months following therapy initiation were $67 \%, 58 \%$, and $53 \%$, respectively, and at 24 months following therapy initiation, rates of discontinuation were $79 \%, 70 \%$, and $64 \%$, respectively. The proportion of discontinuers who reinitiated therapy was higher when a shorter interval was used to define discontinuation. This is not surprising, as shorter gaps in therapy indicate temporary interruptions rather than discontinuation per se. When the allowable gap period defining discontinuation was varied from 30 to 60 to 90 days, the proportion of discontinuers reinitiating therapy decreased from $58 \%$ to $46 \%$ to $38 \%$, respectively. Regardless of the allowable gap period, however, the observed patterns of discontinuation and reinitiation were similar, as were the findings in the multivariable Cox model. Study findings did not change appreciably when analyses were repeated in a cohort of women required to have $\geq 12$ months versus $\geq 24$ months of post-index follow-up (data not shown).

\section{Discussion}

In this study of commercially insured women who were newly initiated on osteoporosis therapy, we found that only a small proportion remained continuously on therapy without interruptions. Women tended to discontinue therapy fairly soon after initiation, with the biggest decline in persistence occurring within 6 months of therapy initiation. Approximately half of those who discontinued treatment returned to therapy, and the majority of reinitiations occurred within 6 months of therapy interruption. Despite the fact that almost half of discontinuers returned to therapy within months of the interruption, they remained consistently on therapy for only about 2-6 months following reinitiation. Those who discontinued treatment early were less likely 
Table I Demographic and clinical characteristics of study population during the pre-index baseline period

\begin{tabular}{|c|c|c|c|c|}
\hline & $\begin{array}{l}\text { Continuous users } \\
N=28,246 \\
n(\%)\end{array}$ & $\begin{array}{l}\text { Discontinuers who } \\
\text { remained off therapy } \\
N=34,873 \\
n(\%)\end{array}$ & $\begin{array}{l}\text { Discontinuers who } \\
\text { reinitiated therapy } \\
N=29,720 \\
\text { n (\%) }\end{array}$ & $\begin{array}{l}\text { Total } \\
\mathrm{N}=92,839 \\
\text { n (\%) }\end{array}$ \\
\hline \multicolumn{5}{|l|}{ Age group, years } \\
\hline $55-59$ & $7355(26.0)$ & $8640(24.8)$ & $8362(28.1)$ & $24,357(26.2)$ \\
\hline $60-64$ & $628 I(22.2)$ & $7192(20.6)$ & $6518(21.9)$ & $|9,99|(21.5)$ \\
\hline $65-69$ & $3722(13.2)$ & $4474(12.8)$ & $3707(12.5)$ & $11,903(12.8)$ \\
\hline $70-74$ & $3566(12.6)$ & $4285(12.3)$ & $3533(11.9)$ & $11,384(12.3)$ \\
\hline $75-79$ & $3338(11.8)$ & $4318(12.4)$ & $3316(11.2)$ & $10,972(11.8)$ \\
\hline $80-89$ & 3655 (12.9) & $5305(15.2)$ & 3844 (12.9) & $12,804(13.8)$ \\
\hline$\geq 90$ & $329(1.2)$ & 659 (1.9) & $440(1.5)$ & $1428(1.5)$ \\
\hline \multicolumn{5}{|l|}{ Geographic location (USA) } \\
\hline Northeast & $2605(9.2)$ & $3005(8.6)$ & $2487(8.4)$ & $8097(8.7)$ \\
\hline Midwest & $9614(34.0)$ & II,837 (33.9) & $9854(33.2)$ & $31,305(33.7)$ \\
\hline South & $9376(33.2)$ & $|3,48|(38.7)$ & II,805 (39.7) & $34,662(37.3)$ \\
\hline West & $6601(23.4)$ & $6447(18.5)$ & $5467(18.4)$ & $18,515(19.9)$ \\
\hline Unknown & $50(0.2)$ & $103(0.3)$ & $107(0.4)$ & $260(0.3)$ \\
\hline Osteoporosis diagnosis & $9248(32.7)$ & $10,027(28.8)$ & $8967(30.2)$ & $28,242(30.4)$ \\
\hline Any osteoporotic fracture & $1012(3.6)$ & $1426(4.1)$ & $1103(3.7)$ & $354 \mid(3.8)$ \\
\hline \multicolumn{5}{|l|}{ Number of comorbidities ${ }^{\mathrm{a}}$} \\
\hline 0 & $626(2.2)$ & $916(2.6)$ & $648(2.2)$ & $2190(2.4)$ \\
\hline $1-5$ & $8502(30.1)$ & $9660(27.7)$ & $8031(27.0)$ & $26,193(28.2)$ \\
\hline $6-10$ & $12,223(43.3)$ & $14, \mid 44(40.6)$ & $\mid 2,278(4 \mid .3)$ & $38,645(41.6)$ \\
\hline$\geq \mathrm{II}$ & $6895(24.4)$ & $10,153(29.1)$ & $8763(29.5)$ & $25,8 I I(27.8)$ \\
\hline \multicolumn{5}{|l|}{ Number of hospitalizations } \\
\hline 0 & $24,738(87.6)$ & $29,517(84.6)$ & $25,535(85.9)$ & $79,790(85.9)$ \\
\hline$\geq 1$ & $3508(12.4)$ & $5356(15.4)$ & $4185(14.1)$ & $13,049(14.1)$ \\
\hline \multicolumn{5}{|c|}{ Number of unique medication classes ${ }^{\mathrm{b}}$ (categorized) } \\
\hline 0 & $1502(5.3)$ & $1603(4.6)$ & $1297(4.4)$ & $4402(4.7)$ \\
\hline $1-4$ & $9023(31.9)$ & $9711(27.8)$ & $7819(26.3)$ & $26,553(28.6)$ \\
\hline $5-10$ & $11,904(42.1)$ & $\mid 4,486(4 \mid .5)$ & $12,694(42.7)$ & $39,084(42.1)$ \\
\hline$\geq \mathrm{II}$ & $5817(20.6)$ & $9073(26.0)$ & $7910(26.6)$ & $22,800(24.6)$ \\
\hline \multicolumn{5}{|c|}{ Number of outpatient visits (categorized) } \\
\hline 0 & $621(2.2)$ & $905(2.6)$ & $643(2.2)$ & $2169(2.3)$ \\
\hline $1-5$ & $5274(18.7)$ & $6317(18.1)$ & $5179(17.4)$ & $16,770(18.1)$ \\
\hline $6-10$ & $7473(26.5)$ & $8292(23.8)$ & $7336(24.7)$ & $23,101(24.9)$ \\
\hline$\geq 11$ & |4,878 (52.7) & $19,359(55.5)$ & $16,562(55.7)$ & $50,799(54.7)$ \\
\hline Receipt of DXA test & $19,338(68.5)$ & $20,440(58.6)$ & $17,858(60.1)$ & $57,636(62.1)$ \\
\hline \multicolumn{5}{|c|}{ Initial osteoporosis therapy prescribed } \\
\hline Oral BP daily & $156(0.6)$ & $259(0.7)$ & $184(0.6)$ & $599(0.6)$ \\
\hline Oral BP weekly & $18,277(64.7)$ & $2 \mathrm{I}, 405(6 \mathrm{I} .4)$ & $19,025(64.0)$ & $58,887(63.4)$ \\
\hline Oral BP biweekly & $97(0.3)$ & $124(0.4)$ & $\mathrm{II}(0.4)$ & $332(0.4)$ \\
\hline Oral BP monthly & $5938(21.0)$ & $7706(22.1)$ & $6251(21.0)$ & $19,895(21.4)$ \\
\hline Raloxifene & $2819(10.0)$ & $2907(8.3)$ & $2300(7.7)$ & $8026(8.6)$ \\
\hline Teriparatide & $412(1.5)$ & $397(1.1)$ & $301(1.0)$ & $1110(1.2)$ \\
\hline Calcitonin (oral or nasal spray) & $547(1.9)$ & $2075(6.0)$ & $1548(5.2)$ & $4170(4.5)$ \\
\hline
\end{tabular}

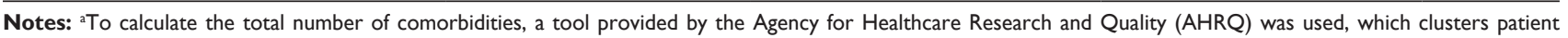
diagnoses and procedures into a manageable number of clinically meaningful categories. ${ }^{25}$ This tool was applied to diagnosis and procedure codes in the database; ${ }^{b}$ the number of prescriptions filled for unique medication classes was evaluated using the therapeutic class variable in the database.

Abbreviations: BP, bisphosphonate; DXA, dual-energy X-ray absorptiometry (test of bone mineral density).

to reinitiate and remained on therapy for shorter periods following reinitiation. Further, older women and those with a recent history of hospitalization were less likely to return to therapy following an interruption. Our study findings were consistent across a variety of sensitivity analyses.
The rates and patterns of therapy utilization described in this study are consistent with other reports in the literature. In studies of government and commercial prescription claims databases ${ }^{19,20,22,26}$ and electronic medical records data, ${ }^{18}$ the reported rates of persistence are in the range of 


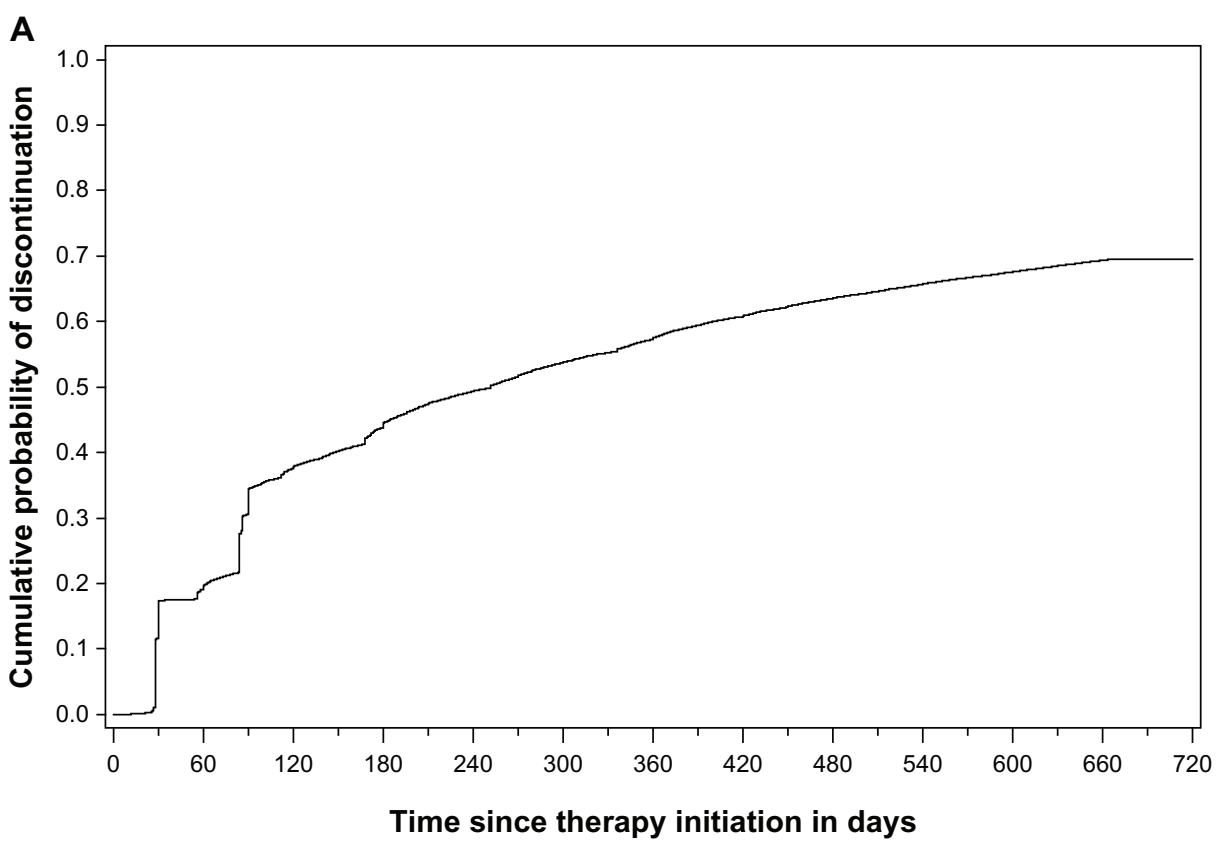

B

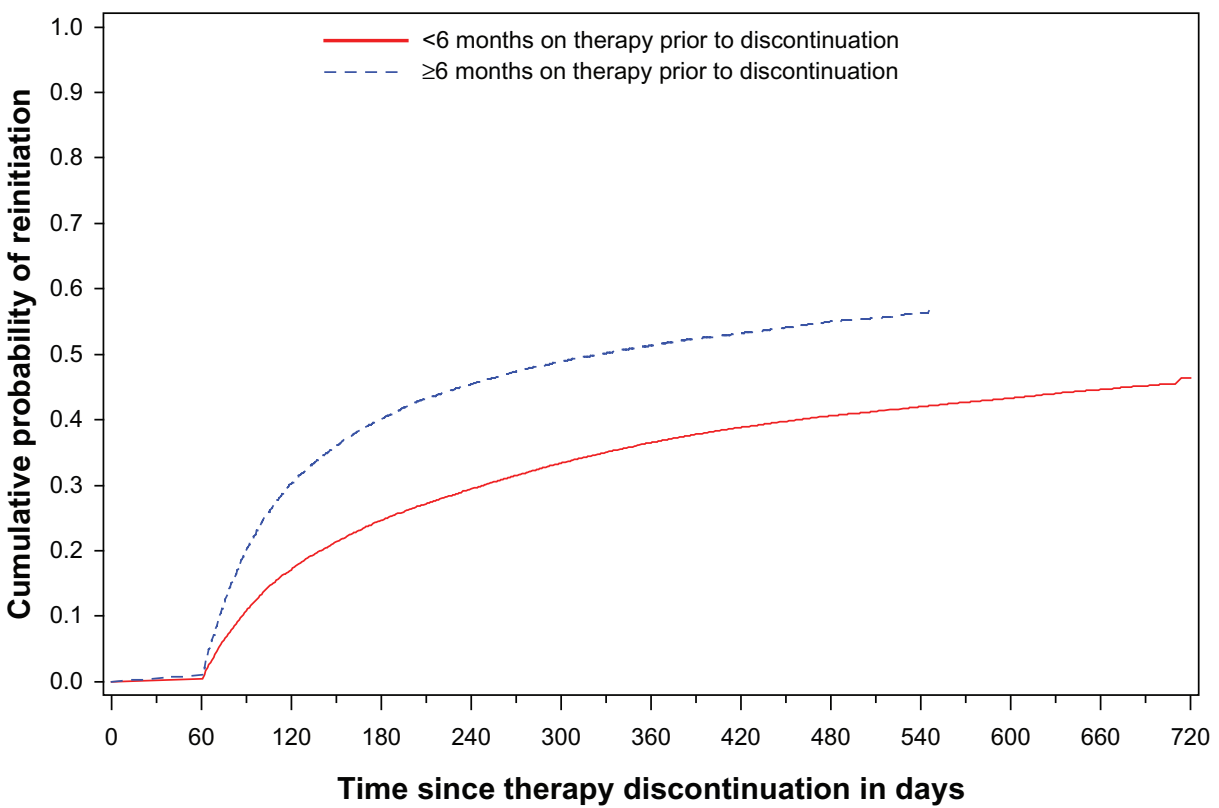

Figure 2 Cumulative probability of (A) therapy discontinuation following initiation of osteoporosis therapy and (B) returning to therapy among those who discontinued treatment, stratified by time on therapy prior to discontinuation.

approximately $40 \%-60 \%, 28 \%-60 \%$, and $16 \%-50 \%$ at 6 months, 12 months, and 24 months of study follow-up, respectively. ${ }^{4,9,10,18-20,22,26}$ Similarly, compliance with osteoporosis medication has been consistently reported to be suboptimal, with average 1-year compliance in the 50\%-60\% range, ${ }^{9}$ and only approximately $40 \%$ of patients being highly compliant $(\geq 80 \%)$ at 1 year. ${ }^{4}$ In these database studies, compliance is typically measured as the proportion of time that the medication is available for use. Although our study focused on persistence, discontinuation, and reinitiation, our findings that the majority of patients discontinue treatment early and exhibit patterns of inconsistent use are in keeping with reports of low medication compliance.

Only a few published studies have examined utilization patterns beyond the first interruption in osteoporosis therapy. In a prospective cohort study, Tosteson et al reported that $25 \%$ of new and existing users discontinued therapy within the 12-month study period; among discontinuers, 49\% reinitiated treatment within the remainder of their 12-month follow-up. ${ }^{17}$ There are a few reports from studies of electronic 
Table 2 Time on therapy following the first treatment gap, among those who reinitiated therapy after a period of discontinuation

\begin{tabular}{lll}
\hline $\begin{array}{l}\text { Time to } \\
\text { discontinuation } \\
\text { (months) }\end{array}$ & $\begin{array}{l}\text { Observation time } \\
\text { remaining at } \\
\text { reinitiation (months) }\end{array}$ & $\begin{array}{l}\text { Days on therapy } \\
\text { following reinitiation, } \\
\text { median (range) }\end{array}$ \\
\hline $0-6$ months & $0-6$ & $58(I$ to I82) \\
& $6-12$ & $90(I 2$ to 365$)$ \\
& $>12$ & $114(10$ to $65 I)$ \\
$\geq 6$ months & $0-6$ & $83(I$ to I82) \\
& $6-12$ & $193(I I$ to 365$)$ \\
& $>12$ & $180(I$ to 486$)$ \\
\hline
\end{tabular}

health records: these studies, like ours, used a 60-day gap to define discontinuation. ${ }^{18,21,22}$ Using 2002-2004 data from a large integrated health care system, Lo et al found that persistence with weekly alendronate among women $\geq 45$ years was $50 \%$ at 12 months following therapy initiation, and that
$37 \%$ of discontinuers reinitiated osteoporosis therapy within 6 months of the interruption. ${ }^{18}$ Brookhart et al investigated a population of elderly (mean age of 82 years), low-income individuals enrolled in a state-sponsored pharmaceutical benefits program in Pennsylvania, USA. ${ }^{21}$ Of the patients who discontinued osteoporosis therapy in the study, $30 \%$ and $50 \%$ reinitiated treatment within 6 and 24 months, respectively, of the interruption. In a recent study of women and men aged $\geq 66$ years in Ontario, Canada, Burden et $\mathrm{a}^{22}$ observed that, within 2 years of therapy initiation, $54 \%$ of patients discontinued therapy, of whom $70 \%$ reinitiated.

Our study builds on these findings, providing recent (2005-2009) data for the US and information on younger women with commercial insurance. Our analysis provides important insights into various underreported aspects of osteoporosis treatment patterns, including the nature of

Table 3 Results of Cox proportional hazards analysis of association between baseline factors and reinitiation of therapy among discontinuers

\begin{tabular}{|c|c|c|c|c|}
\hline Characteristic & $\begin{array}{l}\text { Person-years (discontinuers } \\
\text { who remained off therapy) }\end{array}$ & $\begin{array}{l}\text { Person-years (discontinuers } \\
\text { who reinitiated therapy) }\end{array}$ & $\begin{array}{l}\text { Unadjusted hazard } \\
\text { ratio }(95 \% \mathrm{Cl})\end{array}$ & $\begin{array}{l}\text { Adjusted hazard } \\
\text { ratio }(95 \% \mathrm{Cl})\end{array}$ \\
\hline \multicolumn{5}{|l|}{ Age group, years } \\
\hline $55-59$ & 12,974 & 4259 & Ref & Ref \\
\hline $60-64$ & 10,685 & 3323 & $0.96(0.93-0.99)$ & $0.95(0.92-0.98)$ \\
\hline $65-69$ & 6658 & 1882 & $0.90(0.86-0.93)$ & $0.89(0.86-0.93)$ \\
\hline $70-74$ & 6490 & 1804 & $0.89(0.85-0.92)$ & $0.88(0.85-0.92)$ \\
\hline $75-79$ & 6541 & 1654 & $0.85(0.82-0.88)$ & $0.84(0.8 \mathrm{I}-0.88)$ \\
\hline $80-89$ & 8068 & 1968 & $0.8 \mathrm{I}(0.78-0.84)$ & $0.80(0.77-0.83)$ \\
\hline$\geq 90$ & 1014 & 226 & $0.76(0.69-0.83)$ & $0.76(0.69-0.84)$ \\
\hline \multicolumn{5}{|c|}{ Number of comorbidities ${ }^{\mathrm{a}}$} \\
\hline 0 & 1364 & 328 & Ref & Ref \\
\hline $\mathrm{I}-5$ & 14,523 & 4160 & $1.12(1.03-1.21)$ & $1.05(0.97-1.14)$ \\
\hline $6-10$ & 21,213 & 6205 & $1.16(1.08-1.26)$ & $1.07(0.99-1.16)$ \\
\hline$\geq 11$ & 15,330 & 4423 & $1.16(1.07-1.26)$ & $1.08(0.99-1.17)$ \\
\hline \multicolumn{5}{|c|}{ Osteoporosis diagnosis } \\
\hline No & 37,715 & 10,600 & Ref & Ref \\
\hline Yes & $14,7 \mid 5$ & 4516 & $1.07(1.05-1.10)$ & $1.07(1.04-1.10)$ \\
\hline \multicolumn{5}{|c|}{ Any osteoporotic fracture } \\
\hline No & 50,319 & 14,579 & Ref & Ref \\
\hline Yes & 2111 & 537 & $0.95(0.90-1.01)$ & $1.03(0.97-1.10)$ \\
\hline \multicolumn{5}{|c|}{ Total number of unique medication classes taken ${ }^{\mathrm{b}}$} \\
\hline 0 & 2351 & 646 & Ref & Ref \\
\hline $1-4$ & 14,485 & 4013 & $0.98(0.92-1.04)$ & $0.98(0.92-1.03)$ \\
\hline $5-10$ & 21,789 & 6477 & $1.04(0.98-1.10)$ & $\mathrm{I} .05(0.99-1.1 \mathrm{I})$ \\
\hline$\geq 11$ & 13,805 & 3980 & $1.03(0.98-1.10)$ & $1.07(1.00-1.14)$ \\
\hline \multicolumn{5}{|c|}{ Number of hospitalizations } \\
\hline 0 & 44,285 & 13,022 & Ref & Ref \\
\hline$\geq 1$ & 8144 & 2094 & $0.93(0.90-0.96)$ & $0.94(0.90-0.97)$ \\
\hline \multicolumn{5}{|c|}{ Receipt of DXA test } \\
\hline No & 22,304 & 6279 & Ref & Ref \\
\hline Yes & 30,125 & 8837 & $1.08(1.06-1.11)$ & $1.03(1.00-1.06)$ \\
\hline
\end{tabular}

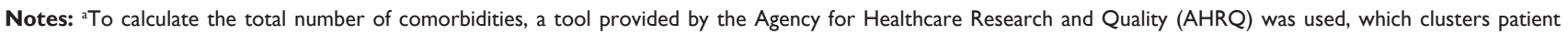
diagnoses and procedures into a manageable number of clinically meaningful categories. ${ }^{25}$ This tool was applied to diagnosis and procedure codes in the database; ${ }^{b}$ the number of prescriptions filled for unique medication classes was evaluated using the therapeutic class variable in the database.

Abbreviations: $\mathrm{Cl}$, confidence interval; DXA, dual-energy X-ray absorptiometry (test of bone mineral density); Ref, reference. 
the interrupted utilization pattern, the duration of time that patients remain on therapy when they do reinitiate after an interruption, and factors that may be associated with therapy reinitiation. Interestingly, our estimates of discontinuation were similar to previous reports suggesting that there has been no noticeable improvement in recent years, despite the focus in clinical research on addressing poor medication-taking behavior. ${ }^{4,9,10,12,14,17-19}$ Our findings regarding the duration on therapy upon reinitiation further indicated a long-term pattern of inconsistent medication use.

Our study has some noteworthy methodological strengths: we evaluated persistence using various definitions of the allowable gap period while most other publications have generally reported a single definition for discontinuation. Lo et $\mathrm{al}^{18}$ and Burden et al, ${ }^{22}$ who varied their allowable gap period, also report that shorter allowable gaps were associated with higher rates of discontinuation. Our study includes 24 months of follow-up; most published studies use a 12-month follow-up period, despite the chronic nature of osteoporosis treatment.

Understanding the factors that might influence therapy utilization behavior, such as whether and how quickly a patient returns to therapy following an interruption, could help guide clinical management and counseling by identifying patients who are at elevated risk of nonpersistence. We found that older women were less likely than younger women to reinitiate therapy following a treatment interruption. As older women are inherently at increased risk of fracture, it is particularly important to find ways to ensure that they remain persistent with therapy. Women with a history of hospitalization in the 12 months preceding therapy initiation were also less likely to reinitiate therapy following an interruption. Women who have been hospitalized might have other ailments that could cause them to deprioritize their needs regarding osteoporosis and might also pose difficulties in complying with osteoporosis medications. Indeed, in their study of low-income, elderly men and women, Brookhart et al found that having a higher number of comorbidities during the 12 months preceding osteoporosis therapy initiation was associated with a lower likelihood of reinitiation. ${ }^{21}$

Our study confirms previous work, ${ }^{21}$ which shows that patients who discontinued early in the course of therapy were less likely to restart therapy following the interruption. Similarly, Tosteson et al reported that new users of osteoporosis therapy had a higher risk of nonpersistence compared to existing users who had been on osteoporosis therapy for at least 6 months at study entry. ${ }^{17}$ We further found that those with shorter periods on therapy prior to an interruption were likely to remain on therapy for shorter periods following reinitiation. This finding - that an individual's previous utilization patterns may predict future utilization patterns - is important, as it suggests that those with a history of nonpersistence are likely to remain at high risk of nonpersistence.

As this study was conducted among commercially insured women who remained enrolled in the database for at least 3 years, we acknowledge that our findings may not generalize to other populations such as women older than 65 years without Medicare supplemental insurance or those enrolled for shorter periods. The overall findings of the sensitivity analysis among women who were enrolled in the database for a shorter period confirmed results in this group. Our study is also susceptible to some limitations associated with using administrative claims data to measure treatment utilization. Measures of adherence using claims data represent refill adherence rather than actual adherence; we cannot know with certainty when a patient actually started and stopped taking medication, nor can we capture medication use that is not reflected in the claims data, such as the use of free medication samples. Our measure of medication use is, however, well established in the literature. ${ }^{19,20,27}$ Claims data may not have allowed us to fully capture physician-, system-, and patientlevel factors that may influence persistence and reinitiation. For example, we could not capture the patient's level of physical function, self-perceived health status, side effects to the medication, or reasons for discontinuing therapy. Studies of self-reported patient data indicate that the presence and severity of side effects is associated with elevated risk of nonpersistence. ${ }^{17,28-31}$ In these studies, approximately $20 \%-30 \%$ of patients reported experiencing side effects to BPs $^{17,28,30}$ (less than $10 \%$ with severe side effects ${ }^{17}$ ) or cited adverse events as their reason for discontinuing medication. ${ }^{31}$ Lastly, this study did not address the effect of dosing regimen on the likelihood of return to therapy, nor the influence of events occurring during the time of therapy prior to reinitiation. While this was beyond the scope of the present study, our preliminary analyses suggest that longer dosing intervals are associated with greater persistence as well as increased likelihood of returning to therapy following an interruption. This observation is in keeping with other reports in the literature. ${ }^{19,20,32}$

\section{Conclusion}

Long-term treatment persistence is an important public health issue, and the increased risk of fracture associated with low persistence and adherence is well established. ${ }^{4}$ In recent years, 
an increasing number of preventive and therapeutic options for osteoporosis have become available. To address the challenge faced by patients in maintaining the high adherence required for therapy effectiveness, newer therapies have tended to utilize expanded dosing intervals. Simultaneously, there is much interest in further understanding patterns and predictors of therapy utilization, with the aim of informing adherence promotion activities. While confirming previous reports of low persistence with osteoporosis therapy, our study found that patients exhibit an interrupted pattern of being on and off therapy, with relatively early interruptions in treatment and short periods of reinitiation. Older and sicker patients, as well as those with a history of nonpersistence, appear to be the most vulnerable to poor persistence behavior. A more thorough investigation of factors associated with discontinuation and reinitiation would potentially require a large prospective study or survey to ascertain factors that are difficult or impossible to capture in database analyses. In recent years, large health care delivery organizations have initiated programs to improve osteoporosis treatment utilization among their patient populations. ${ }^{33,34}$ Evidence from studies such as ours could help inform these efforts to identify patients at greatest risk and improve osteoporosis treatment outcomes.

\section{Acknowledgments}

This study was funded by Amgen Inc. The authors are grateful to Yeshi Mikyas of Amgen Inc for her assistance with formatting and editorial support. These study findings were presented at the Annual Meeting of the American Society of Bone and Mineral Research (September 16-20, 2011, in San Diego, CA, USA).

\section{Disclosure}

Akhila Balasubramanian, Vamshidar Goli, and Cathy W Critchlow are employed at Amgen Inc, which markets Prolia $^{\circledR}$ (denosumab) for the treatment of osteoporosis in postmenopausal women at high risk for fracture. M Alan Brookhart has received research support from Amgen and has also served on advisory boards for Amgen and Pfizer, Inc, but has not received personal compensation for these activities (honoraria declined, given to institution, or donated). The authors report no other conflicts of interest in this work.

\section{References}

1. Boonen S, Autier P, Barette M, Vanderschueren D, Lips P, Haentjens P. Functional outcome and quality of life following hip fracture in elderly women: a prospective controlled study. Osteoporos Int. 2004;15(2): $87-94$.
2. Tosteson AN, Gottlieb DJ, Radley DC, Fisher ES, Melton LJ 3rd. Excess mortality following hip fracture: the role of underlying health status. Osteoporos Int. 2007;18(11):1463-1472.

3. Fast facts on osteoporosis [webpage on the Internet]. Washington, DC: National Osteoporosis Foundation. Available from: http://www.nof.org/ articles/7. Accessed August 20, 2013.

4. Siris ES, Selby PL, Saag KG, Borgstrom F, Herings RM, Silverman SL. Impact of osteoporosis treatment adherence on fracture rates in North America and Europe. Am J Med. 2009;122(Suppl 2):S3-S13.

5. Clinician's Guide to Prevention and Treatment of Osteoporosis. Washington, DC: National Osteoporosis Foundation; 2013. Available from: http://nof.org/hcp/resources/913. Accessed August 20, 2013.

6. Watts NB, Bilezikian JP, Camacho PM, et al; AACE Osteoporosis Task Force. American Association of Clinical Endocrinologists Medical Guidelines for Clinical Practice for the diagnosis and treatment of postmenopausal osteoporosis. Endocr Pract. 2010;16 Suppl 3:1-37.

7. [No authors listed]. Management of osteoporosis in postmenopausal women: 2010 position statement of The North American Menopause Society. Menopause. 2010;17:25-54; quiz 55-56.

8. Curtis JR, Westfall AO, Cheng H, Delzell E, Saag KG. Risk of hip fracture after bisphosphonate discontinuation: implications for a drug holiday. Osteoporos Int. 2008;19:1613-1620.

9. Cramer JA, Gold DT, Silverman SL, Lewiecki EM. A systematic review of persistence and compliance with bisphosphonates for osteoporosis. Osteoporos Int. 2007;18(8):1023-1031.

10. Kothawala P, Badamgarav E, Ryu S, Miller RM, Halbert RJ. Systematic review and meta-analysis of real-world adherence to drug therapy for osteoporosis. Mayo Clin Proc. 2007;82(12):1493-1501.

11. Caro JJ, Ishak KJ, Huybrechts KF, et al. The impact of compliance with osteoporosis therapy on fracture rates in actual practice. Osteoporos Int. 2004; 15:1003-1008.

12. Huybrechts KF, Ishak KJ, Caro JJ. Assessment of compliance with osteoporosis treatment and its consequences in a managed care population. Bone. 2006;38:922-928.

13. McCombs JS, Thiebaud P, McLaughlin-Miley C, Shi J. Compliance with drug therapies for the treatment and prevention of osteoporosis. Maturitas. 2004;48:271-287.

14. Recker RR, Gallagher R, MacCosbe PE. Effect of dosing frequency on bisphosphonate medication adherence in a large longitudinal cohort of women. Mayo Clin Proc. 2005;80:856-861.

15. Ettinger M, Gallagher R, MacCosbe R. Medication persistence with weekly vs. daily doses of oral bisphosphonates. Endocr Pract. 2006;12:522-528.

16. Cramer JA, Lynch NO, Gaudin A-F et al. The effect of dosing frequency on compliance and persistence with bisphosphonate therapy: a comparison of studies in the United States, the United Kingdom, and France. Clin Ther. 2006;28:1686-1694.

17. Tosteson AN, Do TP, Wade SW, Anthony MS, Downs RW. Persistence and switching patterns among women with varied osteoporosis medication histories: 12-month results from POSSIBLE US. Osteoporos Int. 2010;21(10):1769-1780.

18. Lo JC, Pressman AR, Omar MA, Ettinger B. Persistence with weekly alendronate therapy among postmenopausal women. Osteoporos Int. 2006;17(6):922-928.

19. Cramer JA, Amonkar MM, Hebborn A, Altman R. Compliance and persistence with bisphosphonate dosing regimens among women with postmenopausal osteoporosis. Curr Med Res Opin. 2005;21(9): 1453-1460.

20. Solomon DH, Avorn J, Katz JN, et al. Compliance with osteoporosis medications. Arch Intern Med. 2005;165(20):2414-2419.

21. Brookhart MA, Avorn J, Katz JN, et al. Gaps in treatment among users of osteoporosis medications: the dynamics of noncompliance. $\mathrm{Am} \mathrm{J}$ Med. 2007;120(3):251-256.

22. Burden AM, Paterson JM, Solomon DH, Mamdani M, Juurlink DN, Cadarette SM. Bisphosphonate prescribing, persistence, and cumulative exposure in Ontario, Canada. Osteoporos Int. 2012;23:1075-1082.

23. Kaplan EL, Meier P. Nonparametric estimation from incomplete observations. J Am Stat Assoc. 1958;53(282):457-481. 
24. Cox DR. Regression models and life-tables. J R Stat Soc Series B Stat Methodol. 1972;34(2):187-220.

25. Agency for Healthcare Research and Quality. Healthcare cost and utilization project - HCUP: A federal-state-industry partnership in health data. Technical report issued in November, 2010. Available at: http:/www.hcup-us.ahrq.gov/toolssoftware/ccs/CCSUsersGuide.pdf. Accessed on 20 August 2013.

26. Gold DT, Safi W, Trinh H. Patient preference and adherence: comparative US studies between two bisphosphonates, weekly risedronate and monthly ibandronate. Curr Med Res Opin. 2006;22(12): 2383-2391.

27. Siris ES, Harris ST, Rosen CJ, et al. Adherence to bisphosphonate therapy and fracture rates in osteoporotic women: relationship to vertebral and nonvertebral fractures from 2 US claims databases. Mayo Clin Proc. 2006;81(8):1013-1022.

28. McHorney CA, Schousboe JT, Cline RR, Weiss TW. The impact of osteoporosis medication beliefs and side-effect experiences on nonadherence to oral bisphosphonates. Curr Med Res Opin. 2007;23(12): 3137-3152.
29. Tosteson AN, Grove MR, Hammond CS, et al. Early discontinuation of treatment for osteoporosis. Am J Med. 2003;115(3):209-216.

30. Woo C, Gao G, Wade S, Hochberg MC. Gastrointestinal side effects in postmenopausal women using osteoporosis therapy: 1-year findings in the POSSIBLE US study. Curr Med Res Opin. 2010;26: 1003-1009.

31. Ideguchi H, Ohno S, Takase K, Ueda A, Ishigatsubo Y. Outcomes after switching from one bisphosphonate to another in 146 patients at a single university hospital. Osteoporos Int. 2008;19(12):1777-1783.

32. van den Boogaard CH, Breekveldt-Postma NS, Borggreve SE, Goettsch WG, Herings RM. Persistent bisphosphonate use and the risk of osteoporotic fractures in clinical practice: a database analysis study. Curr Med Res Opin. 2006;22(9):1757-1764.

33. Dell R. Fracture prevention in Kaiser Permanente Southern California. Osteoporos Int. 2011;22 Suppl 3:457-460.

34. Newman ED. Perspectives on pre-fracture intervention strategies: the Geisinger Health System Osteoporosis Program. Osteoporos Int. 2011;22:S451-S455
International Journal of General Medicine

\section{Publish your work in this journal}

The International Journal of General Medicine is an international, peer-reviewed open-access journal that focuses on general and internal medicine, pathogenesis, epidemiology, diagnosis, monitoring and treatment protocols. The journal is characterized by the rapid reporting of reviews, original research and clinical studies across all disease areas.

\section{Dovepress}

A key focus is the elucidation of disease processes and management protocols resulting in improved outcomes for the patient.The manuscript management system is completely online and includes a very quick and fair peer-review system. Visit http://www.dovepress.com/ testimonials.php to read real quotes from published authors. 